\title{
CAPSULAR GENU SYNDROME. AN UNDERDIAGNOSED DISORDER.
}

MD Villar Martínez¹, D.M. Garcia Alvarez¹, M.J. Garcia Hernandez¹, T. González Fernández¹, G. González Toledo1, F.J. Carrillo Padilla1.

${ }^{1}$ Hospital Universitario de Canarias, Neurology, La Laguna, Spain.

\section{AIMS}

Capsular Genu Syndrome is a forgotten entity, described by Tatemichi in 1992, which is found in patients with internal capsular genu infaction, disconnecting the thalamus from the orbito-frontal cortex. The clinical presentation varies, although patients usually show behavioral problems, abulia, amnesia, confabulations and lack of insight. Post-stroke cognitive impairment can be found in up to $1 / 3$ of stroke survivors.

\section{METHODS}

A report of two cases assisted in our reference area in 2017

\section{RESULTS}

We present two males, $A$ and $B$, both previously independent and with vascular risk factors. A: 72 years-old man with a previous frontal ictus in 2016, independent after discharge. He developed sudden behaviour changes, with irritability, mood oscillations, apathy and hyporexia. He didn't show any other neurologic deficits, so at first he was labelled as a confusional syndrome. In a brain CT-scan we found a new stroke in the anterior limb of the left internal capsule and thalamus. B: 77 years-old man who after a fall started being abstracted, having episodic memory failures, sleeping disorders and spatial disorientation. In the brain CT-scan was found a lacunar lesion in the right capsular genu.
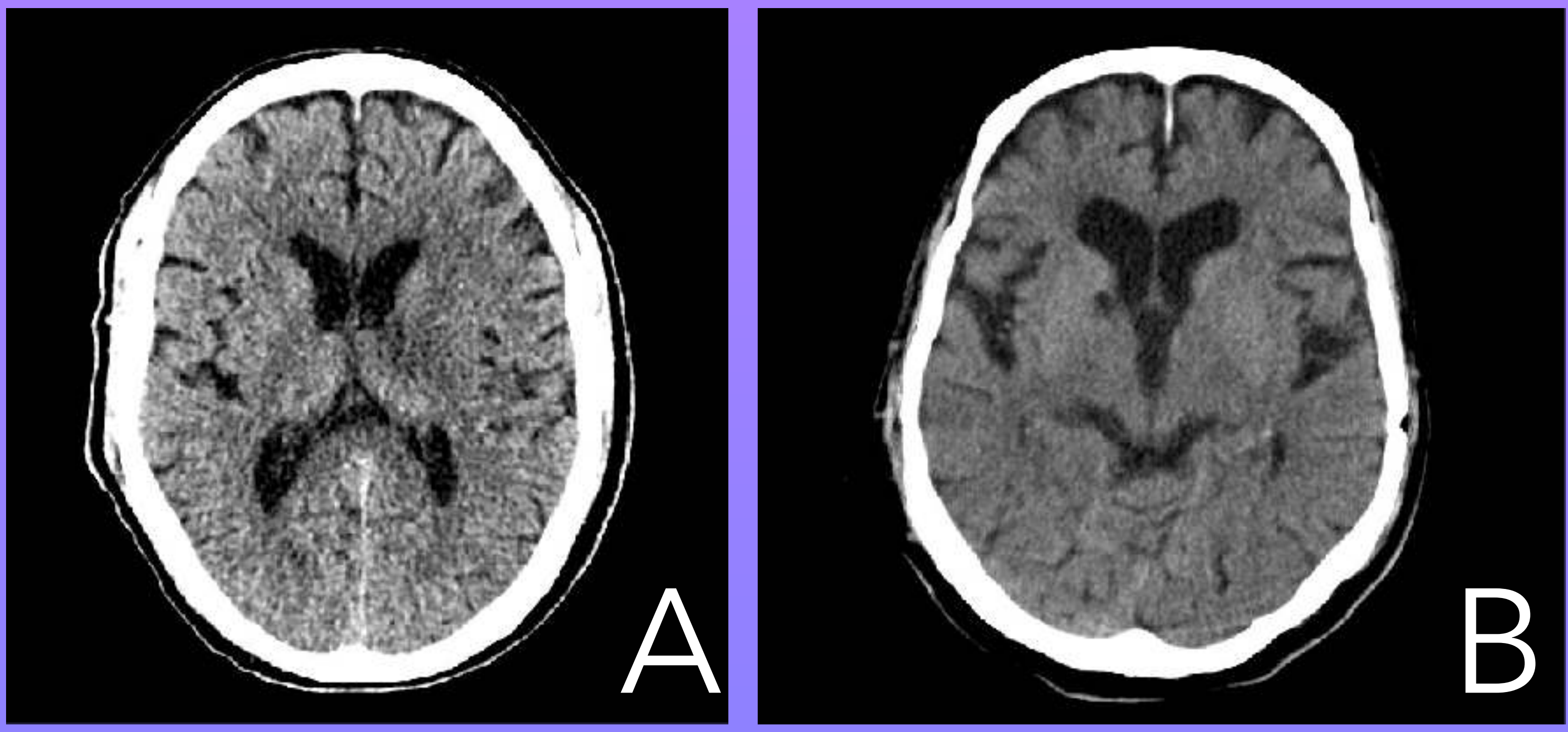

\section{CONCLUSIONS}

Strategic strokes can induce acute cognitive impairment and in some occasions can be misunderstood as a confusional syndrome. These results emphasize the importance of lesion location and the necessity of an assessment of cognition in these cases.

\section{Bibliography:}

1.- Mijajlović et al. Post-stroke Demetia. A comprehensive Review. BMC Medicine (2017) 15:1 DOI 10.1186/s12916-017-0779-7. 2.- Smith $\mathrm{E}$ et al. Correlations between MRI white matter lesioin location and executive function and episodic Memory. Neurology (2011);76:1492-1499.

3.- Schnider a, Gutbrod K, Hess C, Schroth G. Memory without context: Amnesia with confabulations after Infaction of the Right Capsular Genu. Journal of Neurology, neurosurgery and Psychiatry (1996);61:186-193. 